\title{
Erratum to: Recombinant DNA Vaccine Against Inhibition of Neurite Outgrowth Promotes Functional Recovery Associated with Endogeous NGF Expression in Spinal Cord Hemisected Adult Rats
}

\author{
Yi Zhang $\cdot$ Chun-Guang Hao $\cdot$ Li-Qun Hu $\cdot$ \\ Jian Dong $\cdot$ Peng Wei $\cdot$ Dan Xu $\cdot$ Zhi-Cheng Xiao $\cdot$ \\ Ting-Hua Wang
}

Published online: 4 February 2010

(C) Springer Science+Business Media, LLC 2010

Erratum to: Neurochem Res (2009) 34:1635-1641

DOI 10.1007/s11064-009-9951-6

The affiliation for the Corresponding author (Ting-Hua Wang) is hereby replaced with the following: Institute of Neurological Disease, West China Hospital, Sichuan University, 610041 Chengdu, China.

The online version of the original article can be found under doi:10.1007/s11064-009-9951-6.

Y. Zhang · L.-Q. Hu · T.-H. Wang ( $₫)$

Institute of Neurological Disease, West China Hospital,

Sichuan University, 610041 Chengdu, China

e-mail: tinghua_neuron@263.net

Y. Zhang · C.-G. Hao - P. Wei · D. Xu

Institute of Neuroscience, Kunming Medical College,

No. 191, Renmin Western Road, 650031 Kunming, China

L.-Q. Hu

Cadre's Ward, Anhui Provincial Hospital, 230001 Hefei,

China

J. Dong

Department of Biotherapy Center, No 1 Affiliated Hospital,

Kunming Medical College, 650032 Kunming, China

Z.-C. Xiao

Department of Clinical Research,

Singapore General Hospital, Singapore, Singapore 